\title{
Comparing the effect of homogenization and heat processing on the properties and in vitro digestion of milk from organic and conventional dairy herds
}

\author{
D. L. Van Hekken, ${ }^{* 1}$ M. H. Tunick, ${ }^{*}$ D. X. Ren, ${ }^{*} \dagger$ and P. M. Tomasula* \\ *Dairy and Functional Foods Research Unit, Eastern Regional Research Center, Agricultural Research Service, USDA, 600 East Mermaid Lane, \\ Wyndmoor, PA 19038 \\ †Institute of Dairy Science, College of Animal Science, Zhejiang University, Hangzhou 310029, China
}

\begin{abstract}
We compared the effects of homogenization and heat processing on the chemical and in vitro digestion traits of milk from organic and conventional herds. Raw milk from organic ( $>50 \%$ of dry matter intake from pasture) and conventional (no access to pasture) farms were adjusted to commercial whole and nonfat milk fat standards, and processed with or without homogenization, and with high-temperature-short-time or UHT pasteurization. The milk then underwent in vitro gastrointestinal digestion. Comparison of milk from organic and conventional herds showed that the milks responded to processing in similar ways. General composition was the same among the whole milk samples and among the nonfat milk samples. Protein profiles were similar, with intact caseins and whey proteins predominant and only minor amounts of peptides. Whole milk samples from grazing cows contained higher levels of $\alpha$-linolenic (C18:3), vaccenic (C18:1 trans), and conjugated linoleic acids, and lower levels of palmitic (C16:0) and stearic (C18:0) acids than samples from nongrazing cows. Processing had no effect on conjugated linoleic acid and linolenic acid levels in milk, although homogenization resulted in higher levels of $\mathrm{C} 8$ to $\mathrm{C} 14$ saturated fatty acids. Of the 9 volatile compounds evaluated, milk from grazing cows contained lower levels of 2-butanone than milk from nongrazing cows, and milk from both farms showed spikes for heptanal in UHT samples and spikes for butanoic, octanoic, nonanoic, and $N$-decanoic acids in homogenized samples. At the start of in vitro digestion, nonfat raw and pasteurized milk samples formed the largest acid clots, and organic milk clots were larger than conventional milk clots; UHT whole milk formed the smallest clots. Milk digests from graz-
\end{abstract}

Received September 30, 2016.

Accepted April 18, 2017.

${ }^{1}$ Corresponding author: Diane.VanHekken@ars.usda.gov ing cows had lower levels of free fatty acids than digests from nongrazing cows. In vitro proteolysis was similar in milk from both farms and resulted in 85 to $95 \%$ digestibility. Overall, milk from organic/grass-fed and conventional herds responded in similar ways to typical homogenization and heat processing used in United States dairy plants and showed only minor differences in chemical traits and in vitro digestion. Findings from this research enhance our knowledge of the effect of processing on the quality traits and digestibility of milk from organic/pasture-fed and confined conventional herds and will help health-conscious consumers make informed decisions about dairy selections.

Key words: milk, organic, processing, in vitro digestion

\section{INTRODUCTION}

As consumers become more health-conscious in their food choices, their growing demand for organic and grass-fed food products, especially dairy foods, is based on a perception that organic and grass-fed products are healthier than products from conventional sources (Dimitri and Greene, 2000). Fluid milk sales account for $48 \%$ of the 89 million kilograms of organic dairy products sold in the United States as of July 2016 (Organic Dairy Market News, 2016). Differences between organic/grass-fed and conventional fluid milk have been reported (Dhiman et al., 2000; Benbrook et al., 2013; Tunick et al., 2016b) but are often based on raw products and do not account for the effect of processing on the chemical properties and digestibility of the final product.

Standard milk processing includes homogenization and pasteurization, either HTST or UHT. Homogenization involves warming milk to $40^{\circ} \mathrm{C}$ and passing it through a narrow opening to strip off the protective milk fat globular membrane and shatter the lipid droplets into smaller spheres, with an average diameter of 1 to $4 \mu \mathrm{m}$ (Fox and McSweeney, 1998). With the removal of the milk fat globular membrane, homogenized milk 
is more susceptible to hydrolytic rancidity as lipoprotein lipase gains access to lipid substrates. As a fresh product with limited shelf life, milk is pasteurized using either an HTST process $\left(72^{\circ} \mathrm{C}\right.$ for a minimum of 15 s) or a UHT process $\left(135\right.$ to $150^{\circ} \mathrm{C}$ for a minimum of 2 s) to eliminate pathogens, reduce spoilage bacteria, and inactivate many indigenous enzymes. Inactivation of enzymes and denaturation of proteins is more of an issue in UHT than HTST processing. The effects of homogenization and pasteurization of milk have been well established, but the studies focused on overall composition and generally overlooked minor lipids such as n-3 (omega-3) fatty acids and CLA, which are now targeted as beneficial for human health. Very little information is available on how processing affects these minor compounds (Bisig et al., 2007; Butler et al., 2011), and many of the studies that compare milk from grazing and nongrazing cows measured the fatty acids in raw milk or surveyed final products without comparing levels before and after processing.

Information about the effects of processing on the digestibility of milk and the bioavailability of nutrients is limited. A few studies have used particle size to monitor in vitro digestion of milk fat globules (Ye et al., 2011, 2017; Gallier et al., 2012). Related to the present study, Tunick et al. (2016a) examined the in vitro digestion of raw and processed milk from conventional farms and described the effects of homogenization and heat treatment on the chemical (lipid and protein) and physical traits of milk. No information is available that compares the digestibility of milk from organic/grassfed and conventional sources.

The overall objective of this project was to determine whether processing altered the properties of milk from grazing cows and made it different from milk from nongrazing cows. The objectives of the present study were to obtain raw milk from actively grazing organic and nongrazing conventional bovine herds and (1) adjust raw milk to $3.25 \%$ (whole) and $0 \%$ (nonfat) and process using various combinations of homogenization, HTST pasteurization, and UHT treatment; (2) evaluate the chemical qualities (composition, lipid and protein profiles, and volatile compounds) of the processed milk; and (3) compare in vitro digestion (particle size, proteolysis, and lipolysis) of the processed milk.

\section{MATERIALS AND METHODS}

\section{Farms and Milk}

We obtained raw milk from 2 farms located less than $0.5 \mathrm{~km}$ from each other in Berks County, Pennsylvania, which had same weather, soil, and geography conditions. The certified organic milking herd (ORG) con- sisted of 53 cows (40 Holsteins and 13 Jerseys and Jersey crosses) and had a rolling herd average of $6,275 \mathrm{~kg}$ milk, $3.3 \%$ fat, $3.4 \%$ protein, and 358,000 SCC. At the time milk samples were collected, cows were consuming $53 \%$ of their DMI from organic pastures containing alfalfa, orchard and timothy grass, perennial rye, red and white clover, and a small collection of weeds (dandelion, lamb's quarter, plantain, and pigweed). When inside, cows received organic homegrown oat silage and supplements of grain (corn and spelt), kelp meal, and minerals (Tunick et al., 2016b). The conventional milking herd (CONV) consisted of 65 cows (59 Holsteins and 6 Jerseys) and had a rolling herd average of 10,312 $\mathrm{kg}$ of milk, $3.7 \%$ fat, $3.1 \%$ protein, and an SCC of 341,000 cells $/ \mathrm{mL}$. Cows were confined, with no access to pasture, and received a TMR of homegrown corn silage, ryelage, alfalfa haylage, and supplements of grains (corn, wet brewer's grain, and soybeans) and minerals. Approximately $38 \mathrm{~L}$ of milk was obtained 3 different times from each farm over an 8-wk period from early July through early September 2013.

\section{Milk Processing}

Samples were processed in the dairy pilot plant, Eastern Regional Research Center, Wyndmoor, PA. Raw milk was standardized to either $3.25 \%$ fat (whole, Wr) or $<0.1 \%$ fat (nonfat or skim, Sr). Skim milk was HTST-pasteurized at $73^{\circ} \mathrm{C}$ for $15 \mathrm{~s}(\mathbf{S p})$ or UHT pasteurized at $135^{\circ} \mathrm{C}$ for $2 \mathrm{~s}(\mathbf{S u})$, using a FT $74 \mathrm{P} / \mathrm{T}$ HTST/UHT Processing System (Armfield Inc., Denison, IA). Raw whole milk was (1) warmed to $60^{\circ} \mathrm{C}$ and homogenized at 17.2/10.3 MPa using a Universal Pilot Plant (Waukesha Cherry-Burrell, Philadelphia, PA) (Whr); (2) HTST-pasteurized (Wp); (3) homogenized and HTST-pasteurized (Whp); or (4) homogenized and UHT pasteurized (Whu). Aliquots from each treatment were refrigerated at $4^{\circ} \mathrm{C}$ for assays to be completed within $3 \mathrm{~d}$ or frozen immediately $\left(-35^{\circ} \mathrm{C}\right)$ for later analyses.

\section{In Vitro Digestion of Milk}

Raw and processed whole and nonfat milk samples were digested as described by Tunick et al. (2016a). Briefly, $100 \mathrm{~mL}$ of milk at $37^{\circ} \mathrm{C}$ was diluted with $50 \mathrm{~mL}$ of warmed simulated gastric fluid (US Pharmocopeia, 2012) that contained $0.2 \% \mathrm{NaCl}$ and $0.32 \%$ pepsin (P7000 from porcine gastric mucosa, $\geq 250 \mathrm{U} / \mathrm{mg}$ solid; Sigma-Aldrich Corp., St. Louis, MO), pH 1.2, and adjusted to $\mathrm{pH} 1.5$ using $6 \mathrm{M} \mathrm{HCl}$. The mixture was incubated at $37^{\circ} \mathrm{C}$ in a shaking water bath, and $5-\mathrm{mL}$ aliquots were taken at $0,15,30$, and $60 \mathrm{~min}(\mathbf{G}-\mathbf{0}, \mathbf{G}-\mathbf{1 5}$, G-30, and G-60, respectively). The gastric digest was 
then diluted 1:1 with warmed simulated intestinal fluid (SIF; US Pharmocopeia, 2012) that contained $0.68 \%$ $\mathrm{KPO}_{4}, \mathrm{pH} 6.80$, adjusted to $\mathrm{pH} 7.0$ using $0.2 \mathrm{~N} \mathrm{NaOH}$. Bile salts $(5 \mathrm{mg} / \mathrm{mL}$ of SIF, B8631 porcine bile extract; Sigma-Aldrich Corp.) and pancreatin $(1.6 \mathrm{mg} / \mathrm{mL}$ of SIF, P1750, 250 U/mg, porcine pancreatin; Sigma-Aldrich Corp.) were added, and 5-mL aliquots taken at 0 , 15, 30, 60, 90, and $120 \mathrm{~min}(\mathbf{I}-\mathbf{0}, \mathbf{I}-\mathbf{1 5}, \mathbf{I}-\mathbf{3 0}, \mathbf{I}-\mathbf{6 0}, \mathbf{I}-\mathbf{9 0}$, and $\mathbf{I}-\mathbf{1 2 0}$, respectively). The $\mathrm{pH}$ was not adjusted during digestion beyond the initial adjustments at G-0 and I-0. Aliquots were assayed immediately or frozen and stored at $-35^{\circ} \mathrm{C}$ until analysis.

\section{Chemical and Physical Properties}

Composition. The protein, lipid, lactose, and total solids content of raw and processed milk samples were measured in triplicate using near-infrared spectroscopy (MilkoScan Minor 6; FOSS North America, Eden Prairie, MN) according to AOAC method 972.16 (AOAC International, 2012). Ash was measured in triplicate using AOAC muffle furnace method 945.46 (AOAC International, 2012) and then dissolved in $2 \%$ nitric acid to determine mineral content using inductively coupled plasma-optical emission spectroscopy (Duo 6300 iCAP; Thermo Scientific Inc., Waltham, MA).

Lipids. We generated lipid profiles for initial processed whole milk as described by Tunick et al. (2016a). Briefly, extracted lipids were converted to methyl esters and injected into a GC-flame ionization detector (HP 6980 gas chromatography system; Hewlett-Packard, Santa Clara, CA) equipped with a SP-2380 fused silica capillary column (Supelco, Bellefonte, PA). Reference standards consisted of C4:0 to C24:0 methyl esters and conjugated methyl linoleate (GLC448 and UC-59M, respectively; Nu-Chek Prep, Elysian, MN). Free fatty acid levels in intestinal digests were determined immediately upon collection by titrating a $5-\mathrm{mL}$ aliquot to $\mathrm{pH} 7.00 ; 2.00 \mathrm{mg}$ of free fatty acids $/ \mathrm{mL}$ of $0.05 \mathrm{M}$ $\mathrm{NaOH}$.

Proteins. The digestibility of samples was calculated using equation [1]:

$$
\begin{gathered}
\text { Digestibility }(\%)= \\
{[(\mathrm{Nd}-\mathrm{Ns}) /(\mathrm{Nt}-\mathrm{Ns})] \times 100 .}
\end{gathered}
$$

Digested nitrogen (Nd) samples were obtained from a 1:1 mixture of I-120 digest:20\% trichloroacetic acid, centrifuged at $3,000 \times g$ for $30 \mathrm{~min}$ at $22^{\circ} \mathrm{C}$, and the supernatant dried at $110^{\circ} \mathrm{C}$. Total nitrogen $(\mathbf{N t})$ values were obtained from the I-120 digests dried at $110^{\circ} \mathrm{C}$. Soluble nitrogen (Ns) values were obtained from a 1:1 mixture of nondigested processed milk:20\% trichloroacetic acid, centrifuged, and the supernatant dried at $110^{\circ} \mathrm{C}$. Nitrogen levels $(\mathrm{n}=2)$ in Nt, Ns, and Nd samples were determined using a nitrogen analyzer (Flash EA1112; Thermo Fisher Scientific, Lakewood, NJ).

Protein-peptide profiles were generated for processed milk and digested samples using SDS-PAGE as described by Tunick et al. (2016a). Digested samples were thawed in boiling water to inactivate enzymes. Briefly, thawed samples were desalted (Zeba spin desalting columns, $7 \mathrm{~K}$ MWCO; Thermo Fisher Scientific; and centrifuged at $1,500 \times g$ for $2 \mathrm{~min}$ ), mixed 1:1 with tricine sample buffer (BioRad, Hercules, CA) containing mercaptoethanol, and boiled for $5 \mathrm{~min}$. Proteinpeptide profiles were generated on Criterion 10 to $20 \%$ tricine gradient gels with Tris-tricine-SDS running buffer using a Criterion system (BioRad) operated at $150 \mathrm{~V}, 400 \mathrm{~mA}$, for $65 \mathrm{~min}$. Precision Plus Dual Xtra (BioRad) and low-molecular-weight cut-off (GE Life Sciences, Pittsburgh, PA) references were used to estimate molecular weights. Gels were fixed, stained using Bio-Safe Coomassie (BioRad), and scanned (V700 Photo; Epson, Long Beach, CA). Images were analyzed using Image quant densitometer software (version 8.1; GE Life Sciences).

Volatile Compounds. Volatile compounds were extracted from milk within $2 \mathrm{~d}$ of processing and analyzed using a GC-MS method modified from Tunick et al. (2013). Briefly, a mixture of $10 \mathrm{~mL}$ of milk and $4 \mathrm{~g}$ of $\mathrm{NaCl}$ was sealed in a vial containing $10 \mu \mathrm{L}$ of $100 \mathrm{mg} / \mathrm{kg}$ of 2-methyl-3-heptanone internal standard (Sigma-Aldrich Corp.) and warmed at $40^{\circ} \mathrm{C}$ for $10 \mathrm{~min}$ before a solid-phase microextraction fiber $(50 / 30 \mu \mathrm{m}$ DVB/Carboxen/PDMS Stableflex; Supelco, Bellefonte, PA) was inserted to absorb volatile compounds for 30 min. The fiber was then inserted into a GC-MS system (7890A GC/5975 MS detector; Agilent Technologies, Wilmington, DE) fitted with a DB-5 column $(30 \mathrm{~m}$, $0.25 \mathrm{~mm}$ i.d., $0.25-\mu \mathrm{m}$ film thickness; Agilent Technologies) to desorb for 5 min into a splitless injector held at $250^{\circ} \mathrm{C}$ with a flow rate of $0.6 \mathrm{~mL}$ of helium $/ \mathrm{min}$. Agilent ChemStation software (NIST05) was used to analyze MS results and identify volatiles.

\section{Physical Properties of Digest}

Particle size of samples during digestion were tracked using a particle size analyzer (LA 950V2 Laser Scattering Particle Size Analyzer; Horiba Instruments Inc., Romeoville, IL) as described by Tunick et al. (2016a). Samples were run in triplicate to obtain volume-weighted mean diameters $\left(\mathrm{d}_{43}\right)$ and surface-weighted mean diameters $\left(d_{32}\right)$. 


\section{Statistics}

Data were analyzed using a PROC MIXED statement to conduct ANOVA on a fixed-effect model (version 9.4, SAS Institute Inc., Cary, NC). A Bonferroni least significant difference test was used to determine significant differences $(P<0.05)$. Independent variables for evaluating processed milk included type of farm, processing treatment, replicates, and farm $\times$ treatment interaction. Independent variables for evaluating in vivo data included type of farm, incubation time, farm $\times$ incubation time interactions, and replicates.

\section{RESULTS AND DISCUSSION}

\section{Processed Milk}

Composition. Processing and type of farm had little effect on milk composition outside of expected fat differences between standardized whole and skim milk $(3.25 \pm 0.07$ and $<0.1 \%$ fat, respectively). Whole milk contained $3.23 \pm 0.04 \%$ protein, $4.78 \pm 0.06 \%$ lactose, $12.0 \pm 0.25 \%$ total solids, and $0.68 \pm 0.01 \%$ ash. Skim milk contained $3.17 \pm 0.05 \%$ protein, $4.80 \pm 0.09 \%$ lactose, $8.76 \pm 0.14 \%$ total solids, and $0.70 \pm 0.01 \%$ ash. The mineral content was similar among samples and ranged from 195 to $210 \mathrm{mg} / \mathrm{kg}$ of $\mathrm{Ca}, 210$ to 237 $\mathrm{mg} / \mathrm{kg}$ of K, 99 to $105 \mathrm{mg} / \mathrm{kg}$ of $\mathrm{Na}$, and 165 to 176 $\mathrm{mg} / \mathrm{kg}$ of $\mathrm{P}$.
Lipids. Fatty acid profiles from raw and processed whole milk from grazing and nongrazing cows showed that the main effect of farm type significantly $(P<$ 0.05 ) influenced some fatty acids and processing treatment influenced other fatty acids (Table 1 ). The CONV milk was higher $(P<0.05)$ than the ORG milk for palmitic (C16:0, the predominant SFA in milk) and stearic (C18:0) SFA; 60 to $70 \%$ of fatty acids in bovine milk are SFA. The ORG milk was higher in caproic (C6:0) SFA; myristoleic (C14:1), palmitoleic (C16:1), and vaccenic (C18:1 trans) MUFA; and CLA (isomers of linoleic acid, C18:2; about 75 to $90 \%$ of the CLA in milk is rumenic acid) and $\alpha$-linolenic (C18:3, most abundant $n-3$ fatty acids in milk) PUFA. Previous research involving the paired dairy herds used in this study reported higher levels of CLA while cows were actively grazing and higher linolenic acid throughout the year in ORG milk than in CONV milk (no access to pasture; Tunick et al., 2016b). Dairy cows on pasture have altered fatty acid profiles, with higher levels of PUFA that are thought to be beneficial to human health (Benbrook et al., 2013). The MUFA, which make up 20 to $35 \%$ of the lipids in bovine milk, with myristoleic, palmitoleic, and vaccenic acids present at 1 to $1.5 \%$ each, are believed to have a positive effect on increasing blood concentrations of high-density lipoproteins and lowering low-density lipoproteins (Markiewicz-Keszycka et al., 2013). Vaccenic acid is also a precursor to CLA, which stimulate the immune response, help reduce body weight, aid in bal-

Table 1. Main effects (farm type or processing treatment ${ }^{1}$ ) that influenced the level of fatty acids found in milk from grazing organic (ORG) and confined conventional (CONV) herds

\begin{tabular}{|c|c|c|c|c|c|c|}
\hline \multirow{2}{*}{$\begin{array}{l}\text { Fatty acid }{ }^{2} \\
(\mathrm{~g} / 100 \mathrm{~g} \text { of milk fat })\end{array}$} & \multicolumn{2}{|c|}{ Herd type } & & & & \multirow[b]{2}{*}{$\mathrm{SE}$} \\
\hline & ORG & CONV & & & & \\
\hline Caproic, C6:0 & $1.54^{\mathrm{a}}$ & $1.09^{\mathrm{b}}$ & & & & 0.13 \\
\hline Myristoleic, C14:1 & $1.35^{\mathrm{a}}$ & $1.03^{\mathrm{b}}$ & & & & 0.07 \\
\hline Palmitic, C16:0 & $28.99^{\mathrm{b}}$ & $30.49^{\mathrm{a}}$ & & & & 0.30 \\
\hline Palmitoleic, C16:1 & $1.41^{\mathrm{a}}$ & $1.27^{\mathrm{b}}$ & & & & 0.04 \\
\hline Stearic, C18:0 & $11.48^{\mathrm{b}}$ & $12.62^{\mathrm{a}}$ & & & & 0.34 \\
\hline Vaccenic, C18:1 trans & $3.42^{\mathrm{a}}$ & $2.68^{\mathrm{b}}$ & & & & 0.05 \\
\hline CLA, C18:2 isomers & $0.95^{\mathrm{a}}$ & $0.78^{\mathrm{b}}$ & & & & 0.03 \\
\hline \multirow[t]{3}{*}{$\alpha$-Linolenic, C:18:3 } & $0.72^{\mathrm{a}}$ & $0.49^{\mathrm{b}}$ & & & & 0.04 \\
\hline & \multicolumn{5}{|c|}{ Processing } & \\
\hline & $\mathrm{Wr}$ & Whr & $\mathrm{Wp}$ & Whp & Whu & \\
\hline Caprylic, C8:0 & $1.12^{\mathrm{c}}$ & $1.37^{\mathrm{a}}$ & $1.02^{\mathrm{c}}$ & $1.27^{\mathrm{ab}}$ & $1.22^{\mathrm{ab}}$ & 0.06 \\
\hline Capric, C10:0 & $2.88^{\mathrm{c}}$ & $3.48^{\mathrm{a}}$ & $2.76^{\mathrm{c}}$ & $3.22^{\mathrm{ab}}$ & $3.30^{\mathrm{a}}$ & 0.09 \\
\hline Lauric, C12:0 & $3.44^{\mathrm{c}}$ & $4.00^{\mathrm{a}}$ & $3.39^{\mathrm{c}}$ & $3.71^{\mathrm{ab}}$ & $3.81^{\mathrm{ab}}$ & 0.11 \\
\hline Myristic, C14:0 & $11.06^{\mathrm{c}}$ & $12.76^{\mathrm{a}}$ & $11.24^{\mathrm{c}}$ & $11.83^{\mathrm{ab}}$ & $12.08^{\mathrm{ab}}$ & 0.27 \\
\hline
\end{tabular}

${ }^{\mathrm{a}-\mathrm{c}}$ Means with the same letter within a row were not significantly different, $P>0.05$.

${ }^{1}$ Processing treatments for whole milk included raw $(\mathrm{Wr})$; raw homogenized (Whr); HTST pasteurized (Wp); homogenized and HTST pasteurized (Whp); and homogenized and UHT pasteurized (Whu).

${ }^{2}$ Fatty acids are denoted by number of carbons:number of double bonds. 
ancing serum lipid levels, and contribute to controlling diseases such as high blood pressure and cancer.

Processing treatments affected only 4 SFA: caprylic (C8:0), capric (C10:0), lauric (C12:0), and myristic (C14:0), with the highest levels found in the homogenized samples Whr, Whp, and Whu (Table 1). This was expected because homogenization removes the protective milk fat globular membrane layer as lipid droplets are shattered, increasing surface area and exposing substrates to indigenous milk lipoprotein lipase. Although HTST and UHT pasteurization inactivates this lipase (Deeth, 2006), we had a slight lag time before heat treatments were carried out on homogenized milk, which allowed lipolysis to occur, although not to the extent observed in the raw milk sample. Bovine milk fat contains 60 to $70 \%$ SFA, with palmitic acid predominating. Lauric, myristic, and palmitic SFA are believed to contribute to increasing levels of low- density lipoproteins in blood (Markiewicz-Keszycka et al., 2013). Bisig et al. (2007) reviewed several studies and reported that conventional dairy processing steps did not alter the total CLA in dairy products (milk, butter, yogurt, and several cheeses) although isomer distribution was altered. Pasteurization and UHT processing does not affect CLA content, but microwave heating can decrease the level of CLA. Butler et al. (2011) reported that the level of CLA in cream was not altered significantly when it was processed into butter.

Proteins. Protein profiles were similar $(P>0.05)$ in milk from CONV and ORG herds in response to the same processing conditions (raw and processed milk are in lane 2 of the images in Figure 1; images are representative of typical of protein profiles observed in this study). Overall, protein profiles were typical of fresh milk, with predominant caseins $\left(\alpha_{\mathrm{S1}^{-}}, \alpha_{\mathrm{S} 2^{-}}, \beta-\right.$, and $\kappa-\mathrm{CN})$ in zone 2 , distinct major whey proteins $(\alpha-\mathrm{LA}$
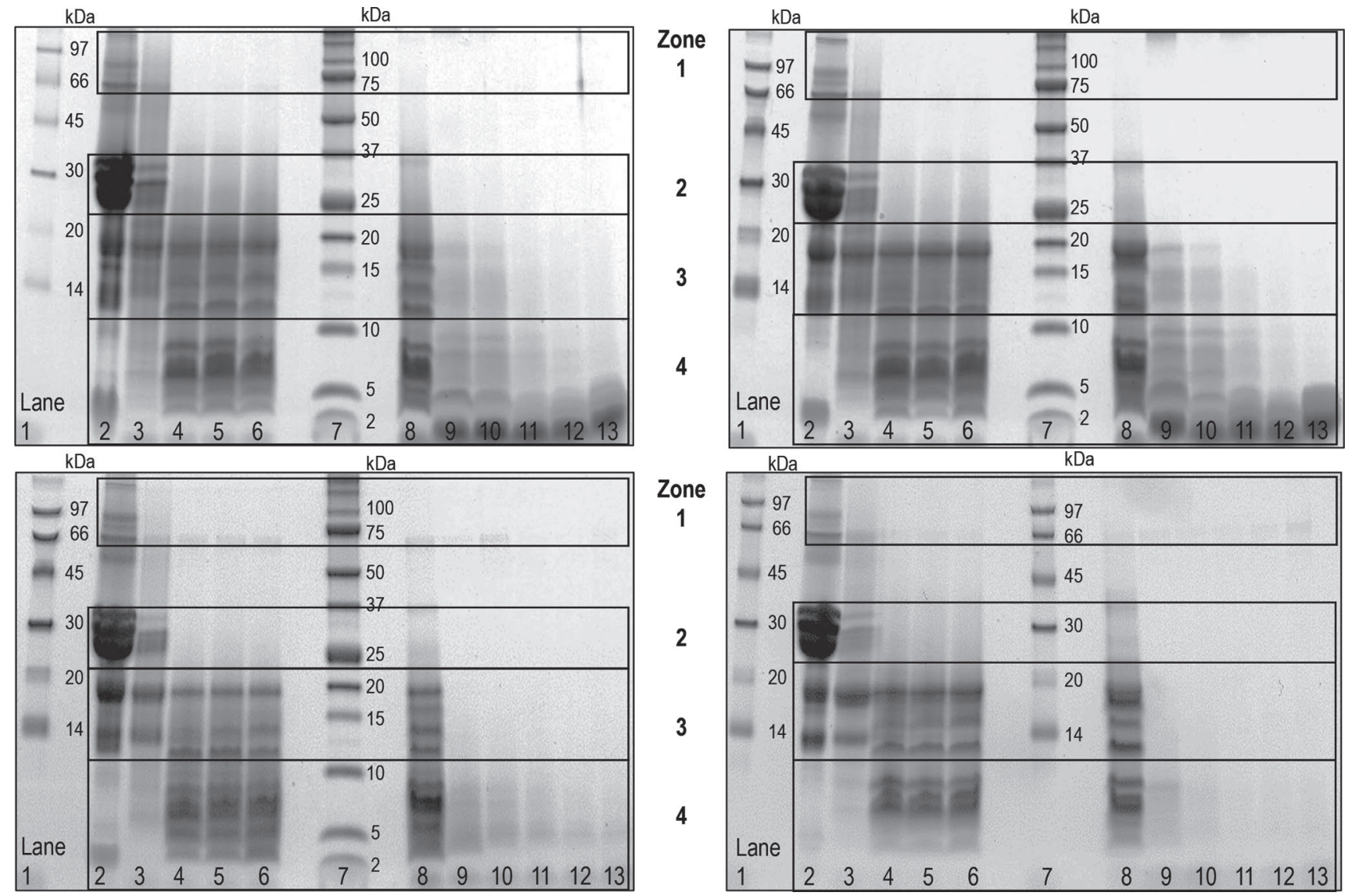

Figure 1. Sodium dodecyl sulfate-PAGE images for proteins and peptides present in (a, b) whole homogenized and (c, d) nonfat milk that were representative of general trends noted in all in vitro gastrointestinal digestions of milk from (a, c) conventional and (b, d) organic cows. Lane 2 shows milk samples before digestion and was representative of all nondigested milk samples. Gastric digests are in lanes 3 ( 0 min), 4 (15 $\mathrm{min}), 5$ (30 $\mathrm{min})$, and 6 (60 min). Intestinal digests are in lanes 8 (0 min), 9 (15 min), 10 (30 min), 11 (60 min), 12 (90 min), and 13 (120 min). Molecular weight standards are in lanes 1 and 7 . Images are divided into 4 zones: (1) minor whey proteins and other high-molecular-weight proteins, (2) native caseins, (3) casein peptides and native whey proteins with a molecular mass between 11 and $19 \mathrm{kDa}$, and (4) small peptides with a molecular mass less than $10 \mathrm{kDa}$. 
and $\beta$-LG) in zone 3 , minor whey proteins in zone 1 , and some minor peptides in zones 3 and 4 . Protein-peptide distributions for raw and processed milk samples were similar $(P>0.05)$ and ranged from 11.6 to $17.9 \%$ in zone $1,33.1$ to $43.8 \%$ in zone $2,35.5$ to $47.3 \%$ in zone 3 , and 2.3 to $13.3 \%$ in zone 4 .

Volatile Compounds. Analysis of GC-MS data showed 9 volatile compounds consistently present at detectable levels in milk samples (Figure 2). Levels of the ketones acetone and 2-butanone (Figures 2a and b), which are associated with sweet fruity aromas (Cheng, $2010)$, were similar $(P>0.05)$ among the raw and processed samples, although levels in raw samples tended to be higher than processed samples. Levels of acetone were similar $(P<0.05)$ in milk from CONV and ORG herds and ranged from 2,176 to 2,810 relative abundance. Levels of 2 -butanone were higher $(P<0.05)$ in CONV milk than in ORG milk; ranging from 734 to $995 \mathrm{RA}$ and 199 to $243 \mathrm{RA}$, respectively.
Short-chained aldehydes, such as nonanal, heptanal, and hexanal (Figures $2 \mathrm{c}$, d, and e), which are associated with green aroma, typically appear early in proteolysis before quickly converting to alcohols and acids (Curioni and Bosset, 2002; Le Quéré and Molimard, 2003). Nonanal levels, which ranged from 33 to 149 RA, were similar $(P>0.05)$ in milk from CONV and ORG herds in the same processing treatment. The Su samples had higher $(P<0.05)$ nonanal levels than CONV Wr and Sr, and ORG Wr, Wp, and Whp. Heptanal levels, which ranged from 0 to $101 \mathrm{RA}$, were similar $(P>0.05)$ among CONV and ORG milk samples within the same processing treatment with UHT (Whu and $\mathrm{Su}$ ) having higher levels $(P<0.05)$ than all other treatments. Hexanal concentrations ranged from 0 to $122 \mathrm{RA}$ for all but 2 samples, CONV Wp and ORG Whu, which were significantly higher at 454 and 532 RA, respectively. Butanoic, nonanoic, octanoic, and N-decanoic free fatty acids, typically found in low amounts in fresh whole

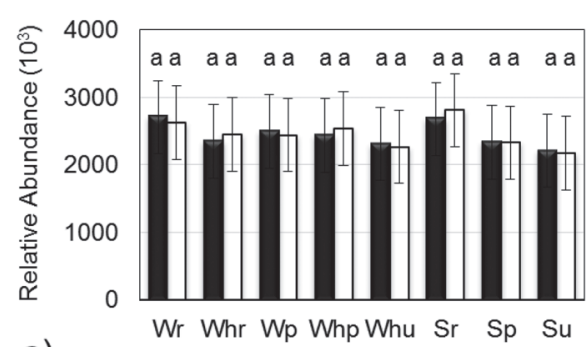

a)

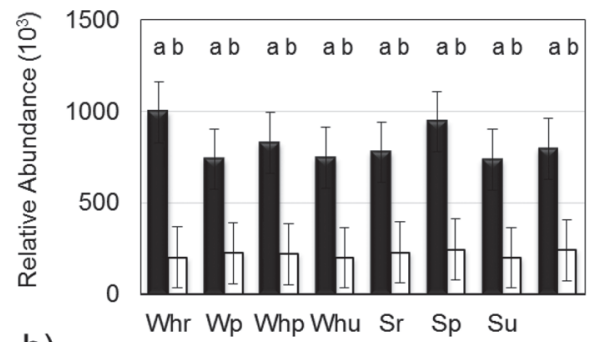

b)

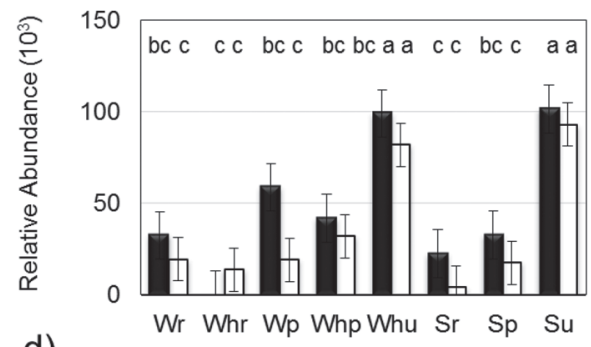

d)

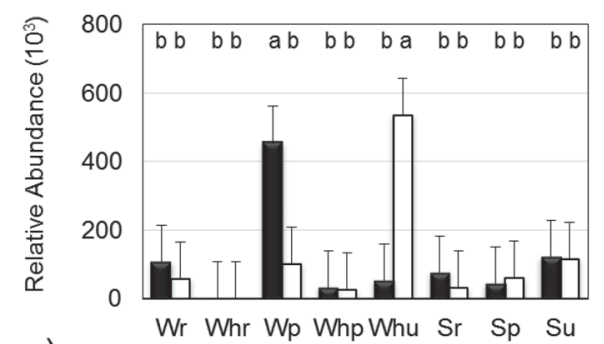

e)

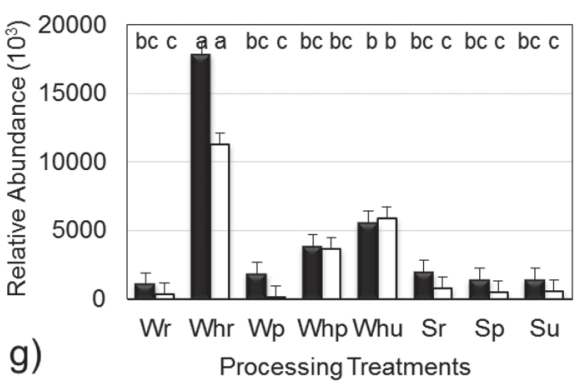

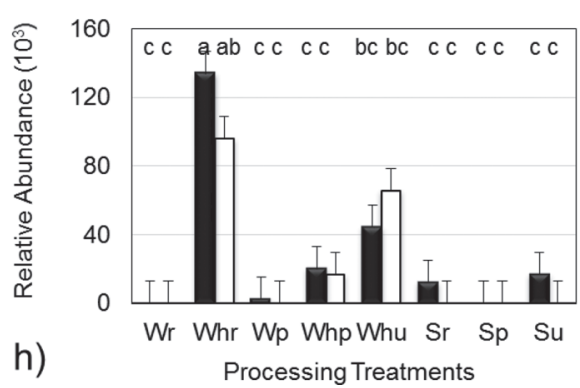

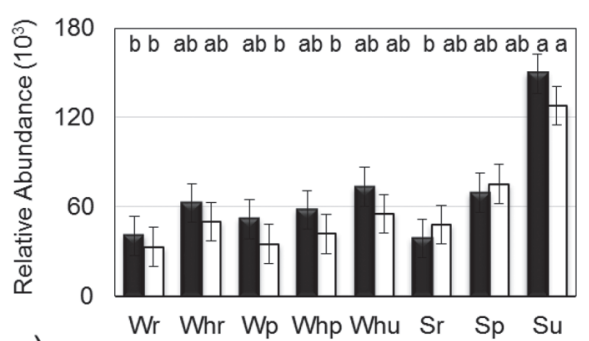

c)

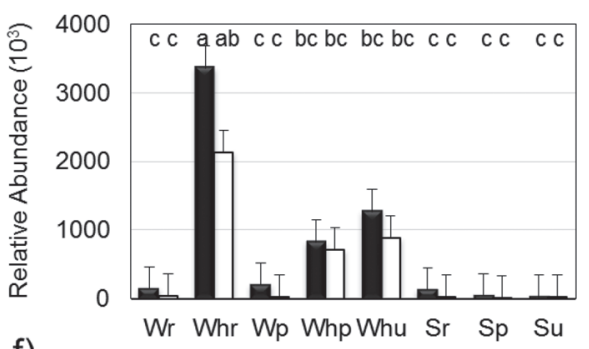

f)

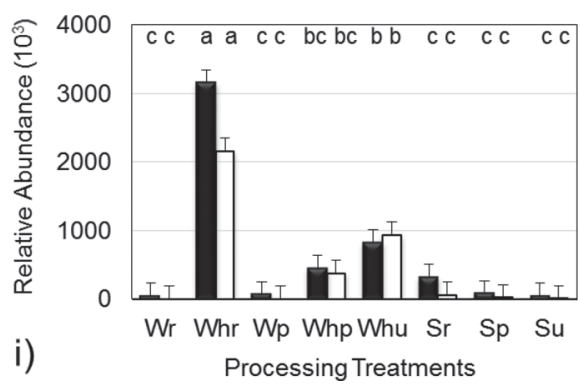

Figure 2. Volatile compounds found in raw and processed milk from conventional (black bars) and organic (white bars) herds. Compounds include (a) acetone, (b) 2-butanone, (c) nonanal, (d) heptanal, (e) hexanal, (f) butanoic acid, (g) octanoic acid, (h) nonanoic acid, and (i) $\mathrm{N}$-decanoic acid. Processing treatments included whole raw (Wr); whole homogenized raw (Whr); whole HTST pasteurized (Wp); whole homogenized and HTST pasteurized (Whp); whole homogenized and UHT pasteurized (Whu); skim raw (Sr); skim HTST pasteurized (Sp); and skim UHT pasteurized $(\mathrm{Su})$. Means not sharing the same letter $(\mathrm{a}-\mathrm{c})$ were significantly different $(P<0.05)$. Standard error bars are shown. 
milk and associated with rancid notes, were quite noticeable in Whr samples, at levels 2 to 3 times higher than in Whu samples and 3 to 4 times higher than in Whp samples. Higher levels of short- and mid-chain fatty acids in homogenized samples may have been associated with the loss of the lipid droplets' protective milk fat globular membrane and the increased surface area that enhanced lipase activity in raw milk. Although indigenous milk lipoprotein lipase is inactivated at HTST and UHT temperatures (Deeth, 2006), the lag time between homogenization and heat treatment in our study allowed some lipolysis to occur.

\section{Digestion of Milk}

Particle Size. Adjusting milk to gastric conditions (salt solution, pepsin, $\mathrm{pH}$ 1.5) at G-0 resulted in clotting of the caseins into large aggregates. Volume-weighted mean particle diameters $\left(\mathrm{d}_{43}\right)$, a parameter preferred for measuring large particles (Figure 3a, CONV milk and Figure 3c, ORG milk), were largest for organic Sp and Sr clots (189 and $180 \mu \mathrm{m}$, respectively), followed by CONV Sp and Sr clots (150 and $138 \mu \mathrm{m}$, respectively), and smallest for Whu samples (ORG, $47.9 \mu \mathrm{m}$; CONV $39.1 \mu \mathrm{m} ; P<0.05)$. Remaining samples were clustered between 84.8 and $114 \mu \mathrm{m}$ for ORG samples and 70 to $111 \mu \mathrm{m}$ for CONV samples. The high temperature of UHT processing has been reported to denature milk proteins and limit aggregation (Douglas et al., 1981) and would account for the reduced size of clots in the UHT samples (Whu and $\mathrm{Su}$ ). It is unclear why ORG milk samples formed larger clots than CONV milk samples. Clot sizes for nonfat milk were larger because fat droplet sizes in whole milk were included in the $d_{43}$ calculations. Changing trends in particle size during in vitro digestion were similar to that reported for conventional milk undergoing similar processing treatments (Tunick et al., 2016a).

A better understanding of smaller particle sizes was obtained using surface-weighted mean diameter $\left(\mathrm{d}_{32}\right.$; Mun et al., 2007). Before digestion began, particle sizes found in conventional (Figure $3 \mathrm{~b}$ ) and organic (Figure 3d) milk had 3 distinct particle sizes. The $\mathrm{Wr}$ and $\mathrm{Wp}$ samples had the largest particles $(7.6$ to $8.3 \mu \mathrm{m})$, to be expected of milk with intact milk fat globular membranes surrounding lipid droplets. Homogenized whole milk samples (Whr, Whp, and Whu) had particle sizes of 4.7 to $5.4 \mu \mathrm{m}$, to be expected after removal of milk fat globular membranes and shattering of droplets into smaller spheres. Skim milk samples had particle sizes of 0.45 to $0.9 \mu \mathrm{m}$, which indicated that casein micelles were being measured. Typical lipid droplet sizes ranged from 0.1 to $20 \mu \mathrm{m}$ in raw milk and 1 to $4 \mu \mathrm{m}$ in homogenized milk, with casein micelles ranging in size from
0.05 to $0.5 \mu \mathrm{m}$, with an average of $0.12 \mu \mathrm{m}$ (Fox and McSweeney, 1998).

After 15 min of shaking in a water bath (G-15), the large milk clots that formed at G-0 had been reduced to smaller particle sizes (9.9 to $13.2 \mu \mathrm{m}$ for whole milk and 10.1 to $16.7 \mu \mathrm{m}$ for nonfat milk). We found no differences $(P>0.05)$ between CONV and ORG samples for each treatment at similar times. Particle sizes were stable $(P>0.05)$ during the remaining gastric digestion until samples were adjusted to intestinal conditions (bile salts, $\mathrm{KPO}_{4}$, pancreatin, $\mathrm{pH}$ 6.80). At I-0, particle sizes decreased $(P<0.05)$ for all treatments, although the decreases for Wr and Wp were not significant. Sizes ranged from 4.8 to $8.1 \mu \mathrm{m}$; UHT samples were the smallest, at 4.8 to $5.3 \mu \mathrm{m}$. By I-15 for ORG milk samples and I-30 for CONV milk samples, particle sizes had stabilized into 2 groups: whole milk digests (8.6 to $11.0 \mu \mathrm{m})$ and skim milk digests (4.1 to $6.5 \mu \mathrm{m})$. Particle sizes at I-60, I-90, and I-120 were significantly higher than those at I-0 and I-15 $(P<0.05)$. We noted no differences $(P>0.05)$ in particle sizes between ORG and CONV milk intestinal digests.

Lipolysis. Lipolysis did not occur during gastric digestion but in vitro intestinal environment and enzymes were very conducive to the release of free fatty acids from milk fat (Figure 4). Based on total free fatty acids accumulated at I-120, 50 to $60 \%$ of the FFA were released during the first $15 \mathrm{~min}$ of intestinal digestion, 70 to $80 \%$ by $30 \mathrm{~min}$, and only minor $(P>0.05)$ increases between I-30 and I-120. As for other properties, homogenization had the greatest effect on lipolysis. As early as 30 min into intestinal digestion, homogenized samples (Whr, Whp, and Whu) released more free fatty acids than Wr and Wp samples and continued to release free fatty acids until leveling off at I-60. Release of free fatty acids was higher in CONV milk (Figure 4a) than in ORG milk (Figure 4b). The CONV milk contained higher amounts of stearic acid, C18:0 (Table 1 ), which is located on the first and third position of the triacylglycerol molecule, preferred sites for lipase activity. Reduction in lipolysis was influenced by the accumulation of product at the lipid droplet surface that limited access to the substrate and reduced lipase activity (Gallier et al., 2012); this did not mimic in vivo conditions, where free fatty acids would be constantly removed. As reported in other in vitro milk digestion studies (Gallier et al., 2012; Tunick et al., 2016a), enhanced lipolysis in homogenized milk samples occurred when the milk fat globular membrane was removed during homogenization and lipid droplet sizes were greatly reduced, thus increasing the total surface area and exposing more lipid substrate to lipases.

Proteolysis. In vitro gastrointestinal digestion of milk resulted in 85.6 to $94.5 \%$ of the proteins being 
degraded after $3 \mathrm{~h}(1 \mathrm{~h}$ in gastric conditions and $2 \mathrm{~h}$ in intestinal conditions). We found only slight, nonsignificant differences $(P>0.05)$ among ORG and CONV milk digests and among processing treatments (Figure $5)$.

High digestibility values were supported by SDSPAGE results. Representative SDS-PAGE gel images of proteolytic trends during gastrointestinal digestion are shown in Figure 1: (a) Whp CONV; (b) Whp ORG; (c) $\mathrm{Su}$ CONV; and (d) Su ORG. The SDS-PAGE gels were divided into 4 zones for densitometer analysis: (1) minor whey proteins; (2) caseins $\alpha_{\mathrm{S1}^{-}}, \alpha_{\mathrm{S2}^{-}}, \beta-$, and $\kappa-\mathrm{CN}$; (3) major whey proteins $\alpha$-LA and $\beta$-LG, and large and medium length peptides, 11-19 kDa molecular mass; and (4) small peptides, $<10 \mathrm{kDa}$ molecular mass. His- tograms of changing proteins and peptides distribution in the 4 zones for the CONV and ORG gels from Figure 1 are shown in Figure 6.

Digestion trends showed rapid hydrolysis of casein and minor whey proteins, and formation of many medium and small peptides during gastric digestion (lanes 3 to 6), and rapid loss of medium peptides and gradual reduction in small peptides and stainable material during intestinal digestion (lanes 8 to 13). Digestion trends were similar to those reported by Tunick et al. (2016a).

In the present study, caseins and major whey proteins were predominant in raw and processed milk before digestion (Figure 1, lane 2). By the time samples had been adjusted to $\mathrm{pH} 1.5$, pepsin added, and the first aliquots of G-0 (Figure 1, lane 3) were taken, caseins had

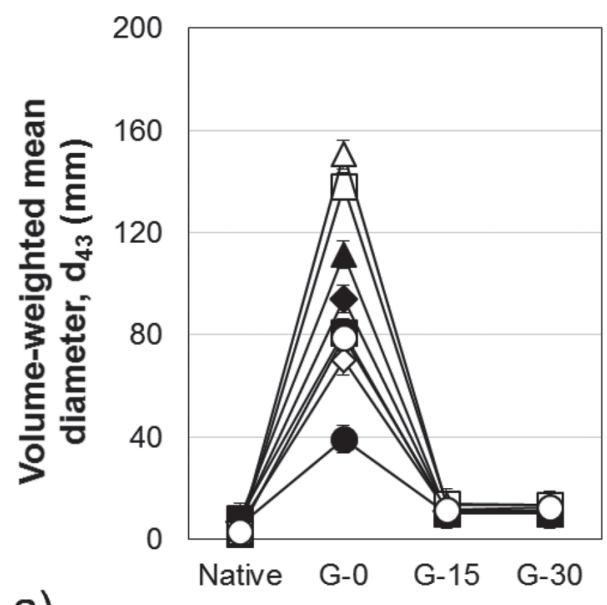

a)

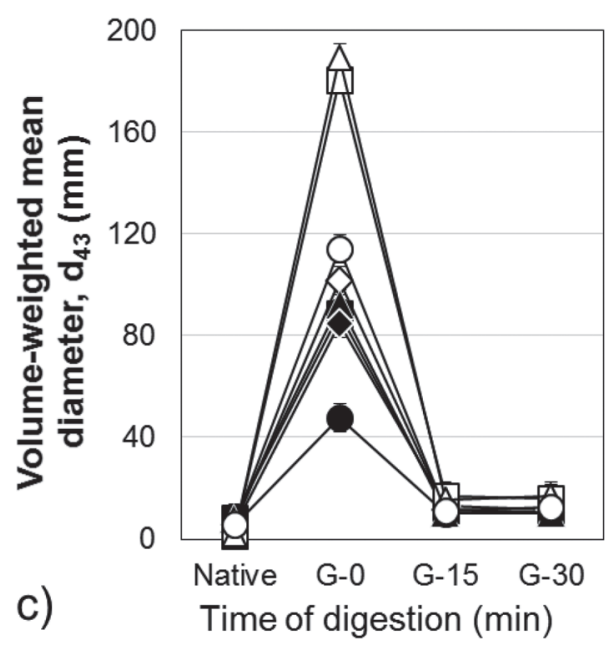

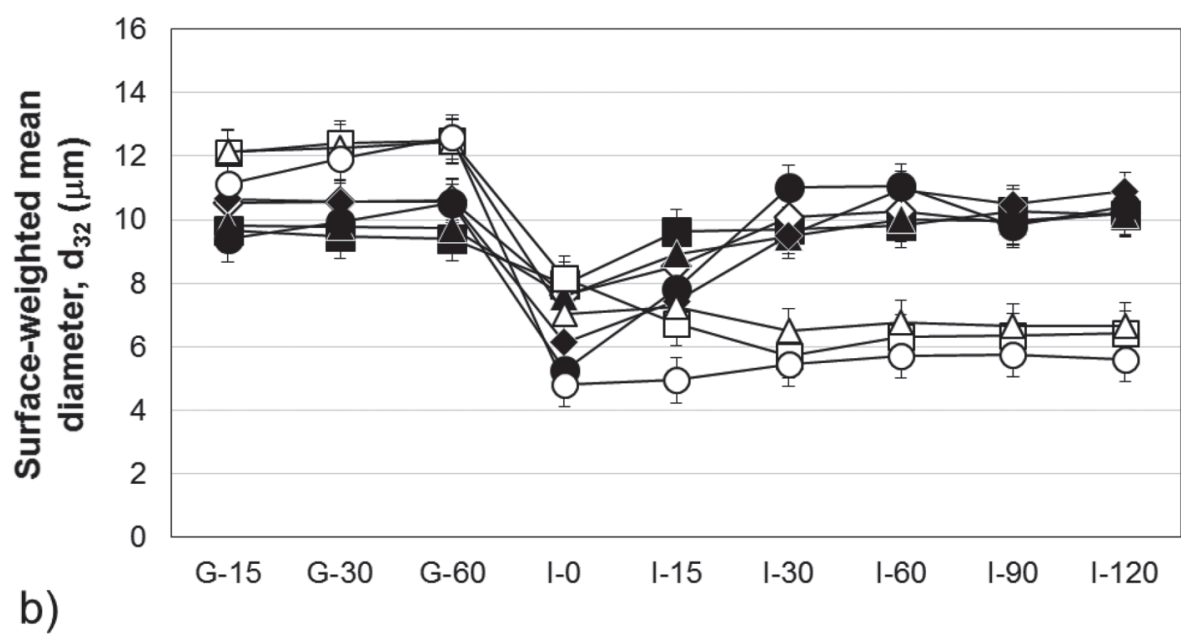

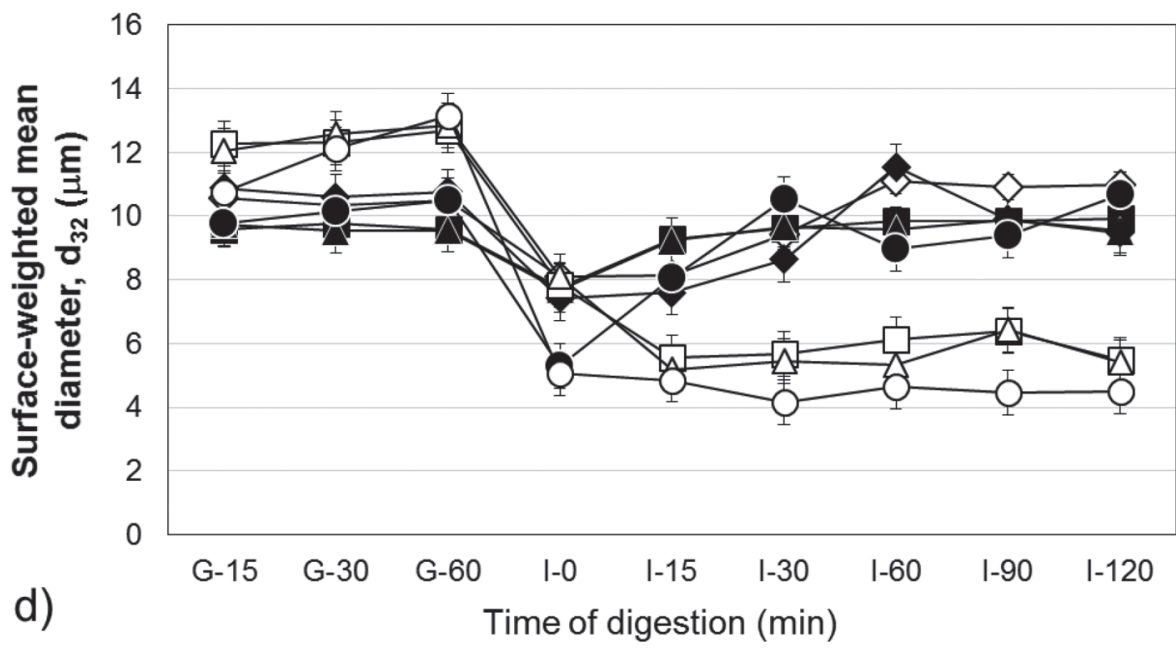

Figure 3. Particle sizes [(a) and (c) volume mean particle diameter, $\mathrm{d}_{43}$, and (b) and (d) surface-weighted mean diameter, $\mathrm{d}_{32}$ ] during in vitro digestion of raw and processed milk from $(\mathrm{a}, \mathrm{b})$ conventional and $(\mathrm{c}, \mathrm{d})$ organic herds. Samples were collected during gastric digestion at 0 , 15 , 30, and 60 min (G-0, G-15, G-30, and G60, respectively); and during intestinal digestion at 0, 15, 30, 60, 90, and 120 min (I-0, I-15, I-30, I-60, I-90, and I-120, respectively). Processing treatments included whole raw (Wr; $\mathbf{0}$ ); whole homogenized raw (Whr; $\diamond)$; whole HTST pasteurized (Wp; $\mathbf{\Delta}$ ); whole homogenized and HTST pasteurized (Whp; $\bullet$ ); whole homogenized and UHT pasteurized (Whu; $)$ ); skim raw (Sr; $\square$ ); skim HTST pasteurized $(\mathrm{Sp} ; \Delta)$; and skim UHT pasteurized $(\mathrm{Su} ; \mathrm{O})$. Standard error bars are shown; bars in (a) and (c) are hidden by symbols. 


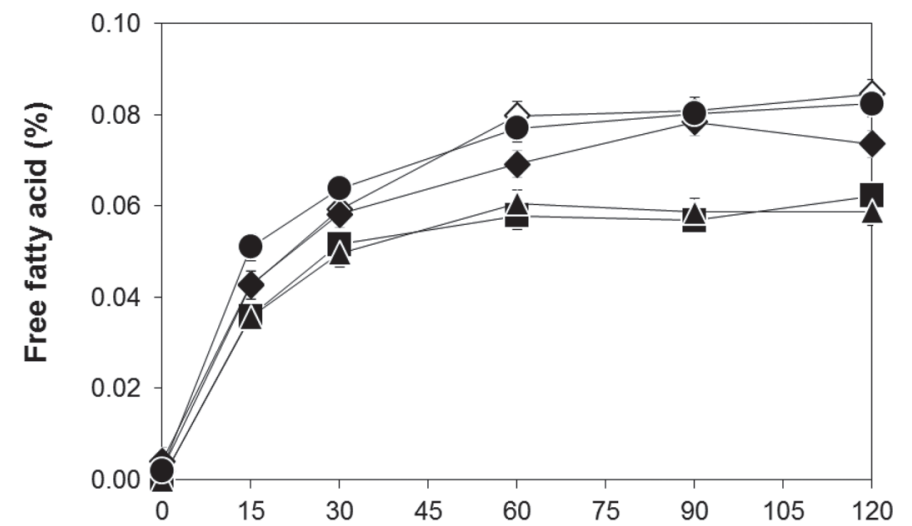

a)

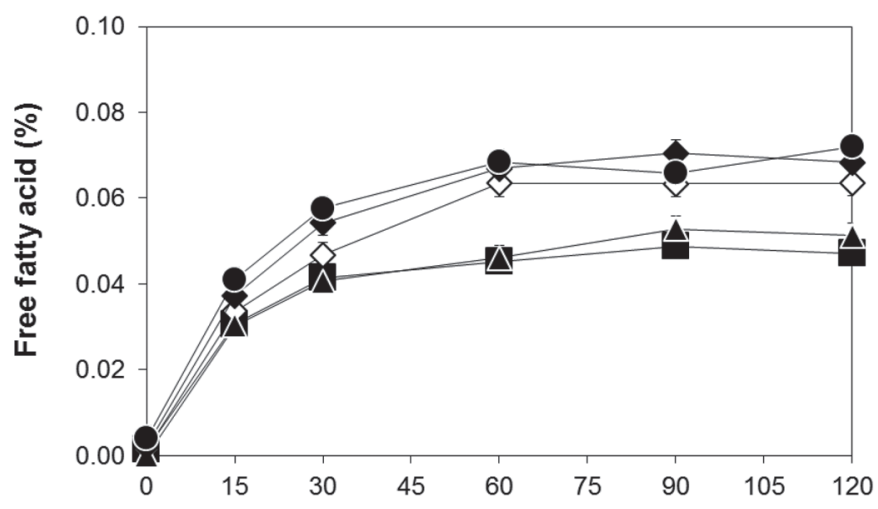

b)

Time of intestinal digestion (min)

Figure 4. Comparison of the levels of free fatty acids released during intestinal digestion of raw and processed milk from (a) conventional and (b) organic herds. Processing treatments included whole raw (Wr; ם); whole homogenized raw (Whr; $\diamond)$; whole HTST pasteurized (Wp; $\mathbf{\Delta}$ ); whole homogenized and HTST pasteurized (Whp; $\bullet$ ); and whole homogenized and UHT pasteurized (Whu; $\bullet$ ). Standard error bars are present, but many are hidden by symbols.

decreased by a third (36-43 to 20-29\%, respectively) and peptides in zone $3(11$ to $19 \mathrm{kDa})$ increased $(P<$ 0.05 ; Figure 6 ). Bands for minor whey proteins and intact caseins were significantly reduced $(P<0.05)$ in G-15, with only trace amounts of residue material left in zone $2(<5 \%$ casein) throughout gastric digestion for all treatments (Figure 1, lanes 3 to 6, and Figure 6). At G-15, conventional Wr, Whr, Wp, Whp, and Sp had more material $(P<0.05)$ in zone 3 than zone 4 and ranged from 51 to $61 \%$ and 31 to $40 \%$, respectively. The distribution of material in zones 3 and 4 was similar $(P$ $>0.05$ ) for all ORG treatments and CONV Sr and $\mathrm{Su}$, ranging from 48 to $52 \%$ and 42 to $48 \%$, respectively. The CONV Whu samples had more material in zone 4 than zone 3 , at 41.8 and $57.0 \%$, respectively. This shift of material from zone 3 to zone 4 indicated faster proteolysis in those samples. Distributions were stable from G-15 to I-0.

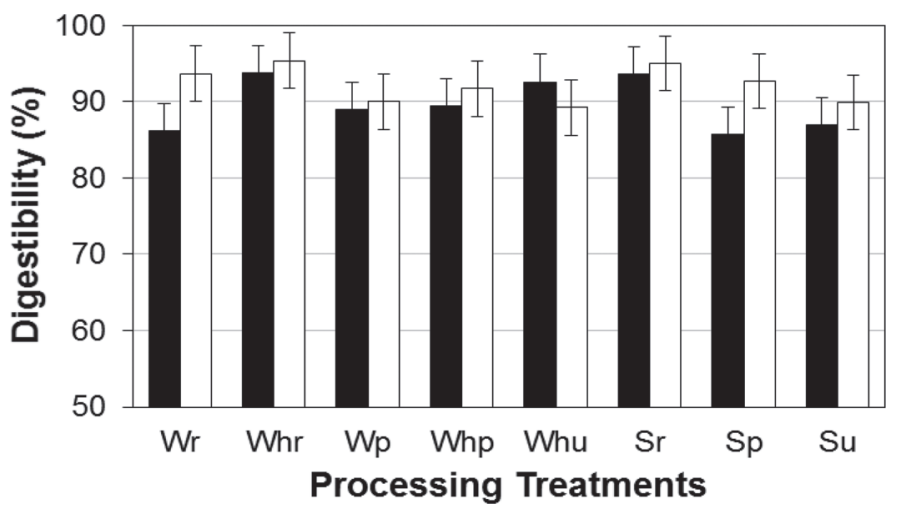

Figure 5. Digestibility of raw and processed milk from conventional (black bars) and organic (white bars) farms after 120 min of intestinal digestion. Processing treatments included whole raw (Wr); whole raw homogenized (Whr); whole HTST pasteurized (Wp); whole homogenized and HTST pasteurized (Whp); whole homogenized and UHT pasteurized (Whu); skim raw (Sr); skim HTST pasteurized (Sp); and skim UHT pasteurized $(\mathrm{Su})$. Standard error bars are shown.

When samples were switched to the intestinal environment by adding phosphate buffer, bile salts, and pancreatin and adjusting to $\mathrm{pH} 7$ (I-0), PAGE images (Figure 1, lane 8) showed a slight realignment of peptides into denser, faster migrating bands in zone 3 (11 to $19 \mathrm{kDa}$ molecular mass), but trend lines (Figure 6) showed no change in material in zone 3 . After $15 \mathrm{~min}$ of intestinal digestion (Figure 1, lane 8), darker peptide bands had been replaced with lighter bands and, as digestion continued, peptides got smaller (faster migration rates) and bands became fainter, indicating loss of stainable material (Figure 1, lanes 8 to 13). With the loss of the casein peptides, faint bands in zone 1 appeared in some samples, suggesting small amounts of material that were very resistant to digestion. Trends lines indicated that the stainable material left in the sample steadily accumulated in zone 4 (Figure 6 a and b) with distribution at I-60, I- 90, and I-120 significantly higher than at I-0. Material in the UHT samples (Whu and $\mathrm{Su}$ ) shifted to zone 4 within the first 15 min of intestinal digestion (Figures $6 \mathrm{c}$ and d). At I-120, zone 4 contained 89.0 to $99.4 \%$ of the remaining material $(P>0.05)$, and we found no significant differences between organic and conventional samples or among the various processing treatments.

The main goal of this study was to determine the effect of processing on organic milk compared to conventional milk, so we undertook careful selection of the farms supplying milk to minimize on-farm variations as much as possible, including region, climate, farm soil type, herd size, and breeds. Because diet was a major difference, farms were identified as actively grazing organic and confined (nongrazing) conventional. Many unidentified factors may also have influenced the milk 


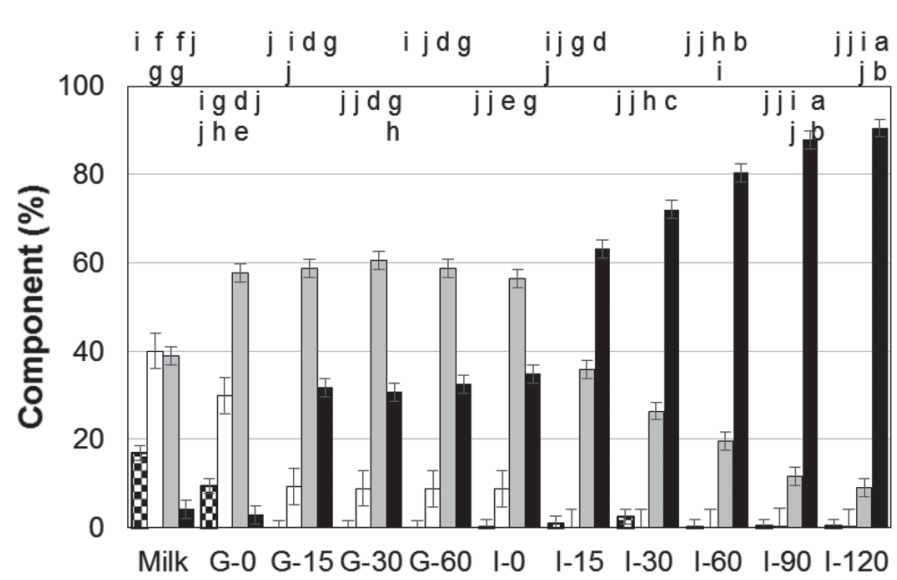

a)

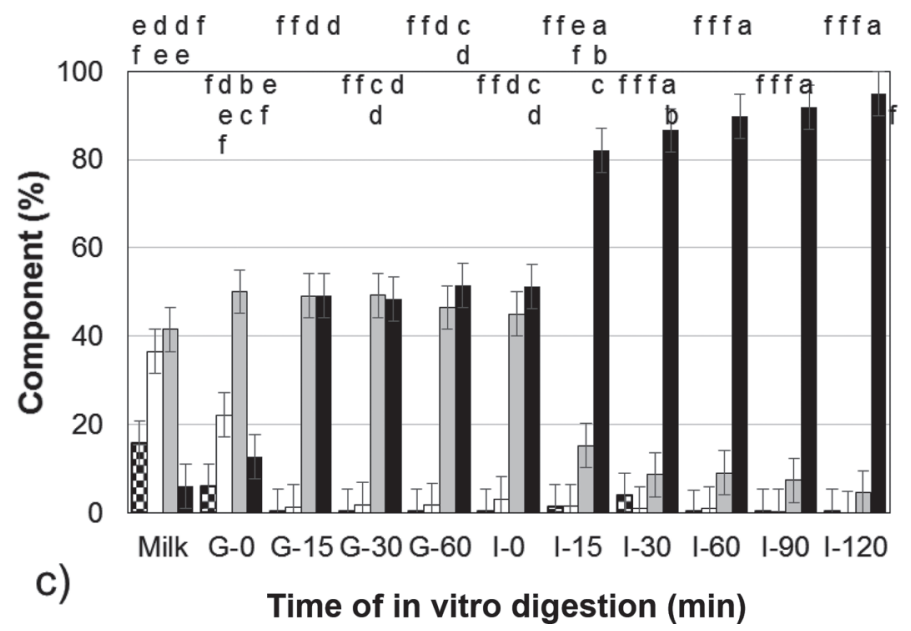

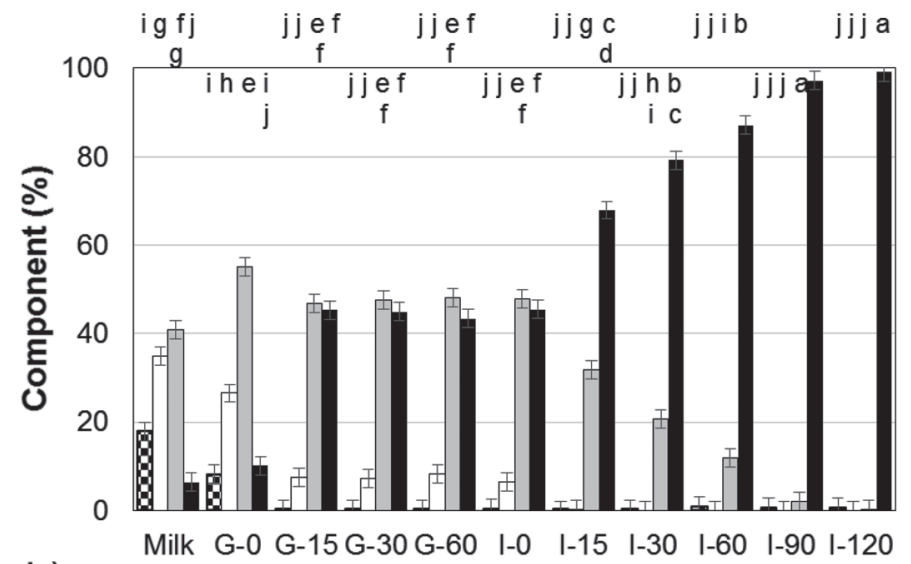

b)

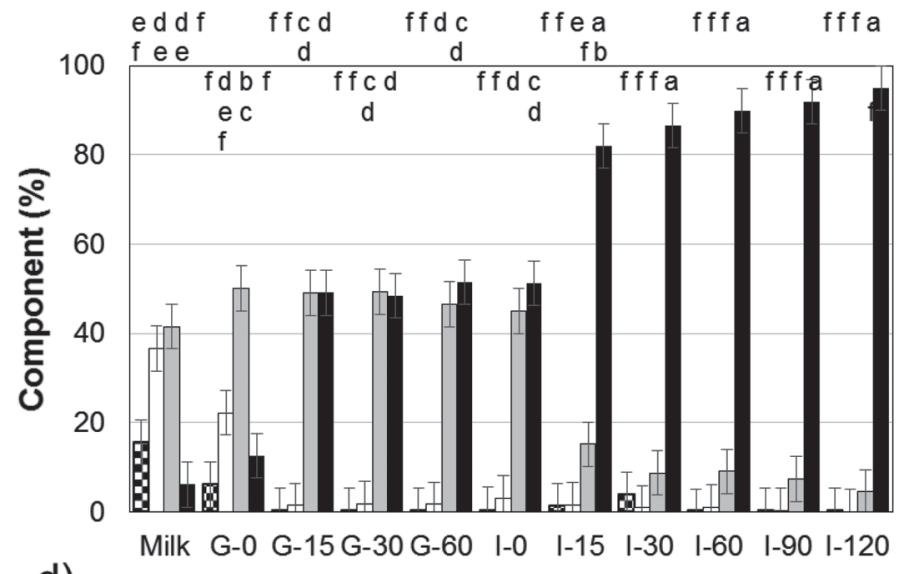

Time of in vitro digestion (min)

Figure 6. Distribution of proteins/peptides during in vitro digestion of (a, b) whole raw and (c, d) skim UHT pasteurized milk from (a, c) conventional and (b, d) organic herds. Samples were collected as follows: undigested; during gastric digestion at 0, 15, 30, and 60 min (G-0, G-15, G-30, and G60, respectively); and during intestinal digestion at 0, 15, 30, 60, 90, and 120 min (I-0, I-15, I-30, I-60, I-90, and I-120, respectively). Distributions of proteins/peptides were combined into zones: (1) minor whey proteins and other high-molecular-weight proteins, checkered bars; (2) native caseins, white bars; (3) casein peptides and native whey proteins with molecular mass between 11 and $19 \mathrm{kDa}$, gray bars; and (4) small peptides with molecular mass less than $10 \mathrm{kDa}$ (black bars). Means within a graph not sharing the same letter (a-j) were significantly different $(P<0.05)$. Standard error bars are shown.

received (Schwendel et al., 2015) and their response to the processing treatments. More research is need to unravel the complex question of what responses were due to farming system (ORG vs. CONV) or farming practices (inclusion of grazing).

\section{CONCLUSIONS}

Milk from actively grazing ORG and confined CONV cows responded in similar ways to typical homogenization, HTST pasteurization, and UHT pasteurization used by the US dairy industry. Only minor differences were noted in the chemical properties and digestion traits of samples from organic and conventional herds. Raw and processed milk from grazing cows had higher amounts of healthy lipids, C18:3 fatty acids, and CLA than milk from cows without access to pasture and indicated that healthy lipids were stable in current processing methods. Findings from this research enhance our knowledge of the effects of processing on the chemical traits and digestibility of milk from grazing ORG and nongrazing CONV herds and will help consumers make informed decisions about their dairy selections.

\section{ACKNOWLEDGMENTS}

The authors thank the following Agricultural Research Service scientists for their contributions: Ray Kwoczak, Susan Iandola, Brien Sullivan, Julia Fischer, and Alberto Nuñez. Mention of commercial products in 
this publication is solely for the purpose of providing specific information and does not imply recommendation or endorsement by the USDA.

\section{REFERENCES}

AOAC International. 2012. Official Methods of Analysis. 19th ed. AOAC International, Gaithersburg, MD.

Benbrook, C. M., G. Butler, M. A. Latif, C. Leifert, and D. R. Davis. 2013. Organic production enhances milk nutritional quality by shifting fatty acid composition: A United States-wide, 18-month study. PLoS One 8:e82429.

Bisig, W., P. Eberhard, M. Collomb, and B. Rehberger. 2007. Influence of processing on the fatty acid composition and the content of conjugated linoleic acid in organic and conventional dairy products - a review. Lait 87:1-19.

Butler, G., J. H. Nielsen, M. K. Larsen, B. Rehberger, S. Stergiadis, A. Canever, and C. Leifert. 2011. The effects of dairy management and processing on quality characteristics of milk and diary products. NJAS Wagening. J. Life Sci. 58:97-102.

Cheng, H. 2010. Volatile flavor compounds in yogurt: A review. Crit. Rev. Food Sci. Nutr. 50:938-950. https://doi. org $/ 10.1080 / 10408390903044081$.

Curioni, P. M. G., and J. O. Bosset. 2002. Key odorants in various cheese types as determined by gas chromatography-olfactometry. Int. Dairy J. 12:959-984.

Organic Dairy Market News. 2016. Organic dairy fluid overview. Organic Dairy Market News 83(38):8.

Deeth, H. C. 2006. Lipoprotein lipase and lipolysis in milk. Int. Dairy J. 16:555-562. https://doi.org/10.1016/j.idairy.j.2005.08.011.

Dhiman, T. R., L. D. Slatter, M. W. Pariza, M. P. Galli, K. Albright, and M. X. Tolosa. 2000. Conjugated linoleic acid CLA content of milk from cows offered diets rich in linoleic and linolenic acid. J. Dairy Sci. 83:1016-1027.

Dimitri, C., and C. Greene. 2000. Recent growth patterns in the US organic foods market. ERS Agriculture Information Bulletin, AIB-777. Accessed Sep. 1, 2016. http://www.ers.usda.gov/media/ 255736/aib777c_1_.pdf.

Douglas, F. W., R. Greenberg, H. M. Farrell, and L. F. Edmondson. 1981. Effects of ultra-high temperature pasteurization on milk proteins. J. Agric. Food Chem. 29:11-15.
Fox, P. F., and P. L. H. McSweeney. 1998. Dairy Chemistry and Biochemistry. Blackie Academic and Professional, London, UK.

Gallier, S., A. Ye, and H. Singh. 2012. Structural changes of bovine milk fat globules during in vitro digestion J. Dairy Sci. 95:35793592.

Le Quéré, J.-L., and P. Molimard. 2003. Cheese flavor. Pages 330-340 in Encyclopedia of Dairy Sci. Vol. 1. J.W. Fuquay and P.F. Fox, ed. Academic Press, London, UK.

Markiewicz-Keszycka, M., G. Czyzak-Runowska, P. Lipinska, and H. J. Wojtowski. 2013. Fatty acid profile of milk-A review. Bull. Vet. Inst. Pulawy 57:135-139. https://doi.org/10.2478/bvip-2013-0026.

Mun, S., E. A. Decker, and D. J. Mc Clements. 2007. Influence of emulsifier type on in vitro digestibility of lipid droplets by pancreatic lipase. Food Res. Int. 40:779-781.

Schwendel, B. H., T. J. Wester, P. C. H. Morel, M. H. Tavendale, C. Deadman, N. M. Shadbolt, and D. E. Otter. 2015. Organic and conventionally produced milk. An evaluation of factors influencing milk composition. J. Dairy Sci. 98:721-746.

Tunick, M. H., S. K. Iandola, and D. L. Van Hekken. 2013. Comparison of SPME methods for determining volatile compounds in milk, cheese, and whey powder. Foods 2:534-543. https://doi. org/10.3390/foods2040534.

Tunick, M. H., D. X. Ren, D. L. Van Hekken, L. Bonnaillie, M. Paul, R. Kwoczak, and P. M. Tomasula. 2016a. Effect of heat and homogenization on in vitro digestion of milk. J. Dairy Sci. 99:41244139. https://doi.org/10.3168/jds.2015-10474.

Tunick, M. H., D. L. Van Hekken, M. Paul, E. Ingham, and H. Darreman. 2016b. Case study: Comparison of milk composition from adjacent organic and conventional farms in the USA. Int. J. Dairy Technol. 69:137-142.

US Pharmacopeia. 2012. Simulated gastric fluid. Page 5778 in The National Formulary 30. Vol. 1. US Pharmacopeia Board of Trustees, Rockville, MD.

Ye, A., J. Cui, D. Dalgleish, and H. Singh. 2017. Effect of homogenization and heat treatment on the behavior of protein and fat globules during gastric digestion of milk. J. Dairy Sci. 100:36-47. https://doi.org/10.3168/jds.2016-11764.

Ye, A., J. Cui, and H. Singh. 2011. Proteolysis of milk fat globule membrane proteins during in vitro gastric digestion of milk. J. Dairy Sci. 94:2762-2770. 